\title{
A prática da teoria na pesquisa em comunicação ${ }^{1}$
}

\author{
José Luiz W. J. G. Braga' \\ https://orcid.org/0000-0003-3742-1119 \\ I - UNISINOS \\ São Leopoldo (RS), Brasil
}

Resumo: O artigo propõe perspectivas integradoras entre teoria e prática no trabalho da pesquisa, voltadas para a superação de uma abordagem dualista. Observa o interesse da proposta para ciências humanas e sociais, assinalando, entretanto, uma relevância especial para a área da comunicação. Depois de caracterizar sumariamente atividade prática, o texto desenvolve reflexões sobre três âmbitos em que fazeres práticos são estruturantes para a teoria: ações requeridas para sua própria gênese; a elaboração expositiva, que ao mesmo tempo constrói e faz circular a teoria; e a realização da teoria por seu acionamento a serviço da pesquisa. O artigo mostra, nesse acionamento, doze ações possíveis. A conclusão explicita a íntima articulação entre aqueles três momentos.

Palavras-chave: pesquisa em Comunicação; teoria e prática; metodologia.

Abstract: The practice of theory in communication research. The article proposes integrative perspectives of theory and practice in research work, aimed at overcoming a dualistic approach. It defends the interest of the proposal for human and social sciences, pointing out, however, a special relevance for the area of communication. After briefly defining practical activity, the text produces reflections on three domains in which practical actions structure theories: actions required for theory generation; the expository formulation, which both constructs and distributes theory; and the activation of theories at the service of research. The article indicates, under this third angle, twelve possible actions. The conclusion makes explicit the inward articulation between those three moments.

Keywords: research in communication; theory and practice; methodology.

A verdadeira teoria é a que se dissipa e se realiza no trabalho científico que ela permitiu produzir (BOURDIEU, 1992, p. 135).

1 O tema do presente texto, antes de sua formulação definitiva, foi debatido com estudantes e professores dos PPGs em Comunicação da UFPA e da Unisinos - aos quais agradeço as contribuições. 


\section{Introdução}

O objetivo do presente artigo é enfatizar um aspecto de nosso trabalho de pesquisadores às vezes deixado à sombra por uma discussão mais vistosa sobre epistemologia reflexiva, teorias e conceitos em visada abstrata. Trata-se do fato de que teorias envolvem uma atividade produtiva e que essa atividade é uma prática.

O que caracteriza a prática é, em primeiro lugar, sua relação com fazeres - implica atividade, tomada de decisão e execução do decidido. Diante dos desafios à ação, há sempre espaço para táticas e estratégias diversificadas, e as decisões são tomadas em vista de resultados não inteiramente previsíveis. É por isso que as atividades práticas comportam algum grau de tentativa, de ensaio-e-erro. O conhecimento das regras práticas requeridas por qualquer processo não se reduz a puro mecanicismo de execução: a boa prática é um cálculo e uma aposta em sua qualidade.

A prática é também relacionada a competências habituais do agente: ter prática é ser escolado em determinado tipo de atividades, tê-las incorporadas de tal modo que, diante da necessidade do gesto, este se faz quase naturalmente em função da eficácia pretendida, maximizando no possível seus resultados.

A prática incorporada é um requisito de qualidade, embora sempre aquém de certezas absolutas sobre os resultados. Não exclui o raciocínio, nem o conhecimento refletido. Se as práticas, em um passado histórico afinal não muito distante, podiam não se expressar - e apenas se adquiriam pelo exercer reiterado -, hoje já não são mudas: suas regras de efetividade se expressam, se manifestam verbal e reflexivamente, mesmo nas profissões mais diretamente manuais. Por maioria de razão, naquelas que implicam o cálculo e o compartilhamento refletido.

Na pesquisa empírica, há reconhecimento habitual das ações práticas - aquelas relacionadas às atividades de campo, de laboratório, de experimentação, busca de depoimentos, trabalhos estatísticos, participações diversas nos ambientes pesquisados. Tais atividades (vamos denominá-las genericamente de observação) envolvem decisões e gestos que se elaboram como exercícios de ordem prática.

Reconhecido esse espaço habitual do exercício da pesquisa, queremos enfatizar o aspecto prático no conjunto das atividades do pesquisador, incluindo, ao lado da ida a campo, as demais atividades da pesquisa - desde a construção do problema a ser investigado, a geração de hipóteses, ao próprio trabalho com a teoria. É fundamental evitar um dualismo, infelizmente não raro, entre esses dois componentes, a teoria e o trabalho material da pesquisa. O dualismo gera uma distinção entre ambos como se fossem coisas de natureza tão diversa que sua articulação só se daria pela submissão de um ao outro. No dualismo é que mais provavelmente se desenvolve o que Luís de Gusmão critica como "fetichismo do conceito" (GUSMÃO, 2012).

Por mais que teorias e conceitos sejam a parte mais rigorosa de nossos processos de pesquisa, estes não funcionam inteiramente dentro da teoria disponível, no conforto 
do conhecimento estabelecido. Diversamente, em boa parte do tempo, devemos sair em terreno desconhecido - e, se nesse espaço trazemos conosco teorias, não é para servi-las ou prestar-lhes obediência, e sim para acioná-las a serviço de nosso objetivo de pesquisa: produzir conhecimento outro, em qualquer abrangência ou complexidade que seja. Nesse espaço, temos o direito (senão mesmo o dever) de tensionar e contestar teorias; e de só acioná-las se efetivamente servirem ao objetivo de descoberta.

As teorias nascem relacionadas a processos práticos. Há componentes na produção teórica e nas teorias constituídas que fazem parte, diretamente, dos âmbitos do fazer, com o que estes impõem de tentativo, de saberes incorporados, de trabalho. A própria elaboração material - a expressão formalizada da teoria - em fórmulas matemáticas, em estruturação argumentativa, em produção de rigor e clareza, implica articulações teórico-práticas. E finalmente, para o exercício da teoria pronta, novas ações são requeridas.

Nos itens subsequentes, vamos refletir sobre esses três ângulos:

a. o que as teorias fazem: em sua gênese;

b. o que as teorias fazem: em sua formulação;

c. o que podemos fazer as teorias fazerem.

A maior parte das reflexões desenvolvidas neste artigo é pertinente para todas as ciências humanas e sociais, mormente quando tratamos de pesquisa qualitativa. Tornam-se centrais, entretanto, para a pesquisa em comunicação, porque boa parte das teorias e conceitos que acionamos é elaborada para questões próprias de outras CHS. Sua transposição para questões comunicacionais exige uma atenção particular para a especificidade das ações da teoria sobre seus objetos de origem; e maior cuidado no acionamento reinterpretativo - como será visto no terceiro item.

\section{O que as teorias fazem}

Para acionar com pertinência as teorias a serviço de nosso objeto de pesquisa é preciso inicialmente perceber o que as teorias fazem.

As teorias fazem as coisas mais diversas: propõem questões, perspectivas, hipóteses, elaboram raciocínios dedutivos e indutivos, fazem inferências abdutivas, apresentam percepções, desenvolvem conceitos, estabelecem relações entre fatos, entre conceitos, entre conceitos e fatos, fazem distinções, explicam, demonstram, argumentam.

Essas ações são desenvolvidas no processo propositivo das teorias e nos textos e encaminhamentos que as expressam. Vamos observar, em dois ângulos distintos, ações inerentes ao processo teórico: aquelas que a teoria exerce em sua própria gênese; e aquelas que desenvolve em sua formulação. 


\subsection{A gênese de teorias}

Karl Popper (2001, p. 17) propõe que

As ciências naturais, bem como as ciências sociais, começam sempre por problemas, pelo facto de algo nos causar espanto, como os filósofos gregos costumavam dizer. Para resolver estes problemas, as ciências usam fundamentalmente o mesmo método que o senso comum emprega, o método da tentativa e erro.

A teoria se caracteriza como uma conjectura sobre a realidade (ou sobre uma questão teórica), que expressa a solução proposta para o problema de partida. Há dois aspectos na citação que relacionam teoria e atividade prática. O primeiro é a relação direta da teoria com o problema ou ordem de questões para as quais busca respostas. Esse é um fazer central de todas as teorias, e que deve ser percebido com especificidade a cada exemplar de proposição teórica observada. Trata-se do gesto de produção da própria teoria, como criação de conhecimento sobre algo que se impõe como um desafio. Mais do que dizer a realidade, o que uma teoria faz é oferecer uma solução: dar resposta a um problema de conhecimento. Conhecer uma teoria exige, portanto, apreender o problema, empírico ou teórico, que ela busca resolver.

O segundo aspecto mostra um momento pré-científico na teoria, que se inicia como tentativa, como baseada em ensaio-e-erro. O movimento inicial da geração teórica é fazer conjecturas - em modo semelhante ao do senso comum, que é o mundo da prática.

O pensamento científico se distingue do senso comum é no trabalho crítico: não se tenta provar que a conjectura é verdadeira, mas inversamente, testa-se de todos os modos possíveis a proposição. Enquanto esta resistir, se viabiliza como teoria aceitável. Essa refutabilidade para a qual a teoria se disponibiliza é o que a caracteriza como científica, para Popper. O processo é expresso do seguinte modo:

minha tese principal é que a novidade da ciência e do método científico, que o distingue da abordagem pré-científica, é a sua atitude conscientemente crítica em relação às tentativas de solução; toma uma parte activa nas tentativas de eliminação, nas tentativas de criticar e falibilizar (POPPER, 2001, p. 26).

Uma parte desse trabalho é desenvolvido pelo próprio proponente de teoria: ele deve verificar o mais possível as questões que permitem refutar suas proposições, levando-o a ajustar, desenvolver ou substituir estas, até que resistam ao que possa implicar objeção.

Naturalmente há limites para esse trabalho interno da produção teórica - seja porque o pesquisador não consegue imaginar outras objeções e outros testes, seja porque está tão convencido da adequação de suas proposições que se torna impermeável à contrariedade. O trabalho crítico se torna, então, externo - isto é, decorrente do debate público 
nas comunidades acadêmicas interessadas (e/ou nos espaços de acionamento prático das teorias). É do debate que dependem as teorias em seu constante aperfeiçoamento ou superação.

No passo inicial de sua apresentação, Popper observa um processo social generalizado em três fases: "o problema > as tentativas de solução > a eliminação [das tentativas mal sucedidas]" (2001, p. 22). Com o trabalho crítico acionado pelo processo científico, passa então a um modelo em quatro fases:

1. o antigo problema;

2. formação de tentativas de teoria;

3. tentativas de eliminação através de discussão crítica, incluindo testes experimentais;

4. os novos problemas, que surgem da discussão crítica das nossas teorias (POPPER, 2001, p. 30, grifos do autor).

A quarta fase expressa a possibilidade de reconstrução dos problemas na esteira da discussão crítica. Adoto essa perspectiva popperiana, tanto no que se refere ao problema como desencadeador de teorias, como no aspecto tentativo (conjectural) da busca de proposições que o solucionem, como ainda na especificidade da crítica intencionada (e, portanto, da falibilização como critério de cientificidade).

Mas é preciso perceber que Popper tem como ponto de partida as ciências experimentais e da natureza, em que é mais provável encontrarmos respostas de tipo sim ou não - ou ainda, na forma de alternativas mutuamente excludentes. Um exemplo dado pelo autor é a discussão da transmissão sináptica entre neurônios. Durante vinte anos, no século XX, discutiu-se se seria elétrica ou química. Nesse espaço, aplica-se o critério de demarcação que o autor propõe: "uma teoria faz parte da ciência empírica se, e apenas se, for contraditória com possíveis experiências e for por isso, em princípio, falibilizável por meio de experiências" (POPPER, 2001, p. 33).

Quando tratamos de ciências humanas e sociais, é preciso ir um pouco além nessa reflexão. A ideia de refutabilidade não corresponde, aqui, tipicamente a um processo binário simples, de decisão entre proposições teóricas que sejam consideradas radicalmente válidas ou não válidas. Considerando a complexidade das $\mathrm{CHS}$, levando em conta os modos como os problemas sejam construídos, uma proposição pode ser mais válida ou menos; sua validade pode ser muito abrangente, para toda uma grande diversidade de questões, ou pode ser pertinente apenas em circunstâncias e situações muito especificadas.

Dada a diversidade das condições de contexto das situações sociais, uma percepção precisa dos âmbitos de validade depende, portanto, de uma discussão constante sobre as características das questões tratadas pelas teorias, e das situações a que se pretendem aplicáveis. Não se trata simplesmente de verificar se uma teoria pode ser assumida como refutável, mas sim de apreender seus âmbitos de validade. 
Nessa perspectiva, podemos sugerir um modelo complementar ao dos quatro passos de Popper, quando lidamos com questões sociais e comunicacionais:

- $\quad$ problema inicial;

- $\quad$ geração de teorias, diversas, conforme os objetos sejam especificados;

- debates críticos e tensionamento mútuo entre teorias próximas;

- $\quad$ caracterização do alcance de validade das proposições teóricas;

- $\quad$ e, com os problemas surgentes, transferências e novas conjecturas.

Nas ciências naturais, dado o padrão experimental, com poucas variáveis, controladas, a percepção das estratégias pode ser matematizada e verificada por lógica formal ou por processos indutivos. Nas teorias interpretativas, de variáveis múltiplas e não controladas, a apreensão das estratégias é mais delicada. Além de uma compreensão precisa do problema enfrentado pelas proposições teóricas, é preciso apreender também as estratégias elaboradas, os objetivos específicos e os encaminhamentos metodológicos realizados pelas teorias.

\subsection{A formulação da teoria - o que esta faz em seus dizeres}

O texto da teoria, o relato da tese, a escrita do artigo são o momento mais comunicacional na produção do conhecimento. Não que os demais momentos não envolvam comunicação, mas aqui esta aparece em suas exigências mais evidentes, porque o que circula no mundo, transformado em percepção e experiência, e é apreendido pela teoria, agora se constrói como oferta de conhecimento para outra circulação.

Uma teoria não é simplesmente um conjunto de proposições sobre a realidade do mundo - é um trabalho sobre este, envolvendo a construção de um problema e uma elaboração da pesquisa encaminhada.

Não basta conhecer as principais proposições, ou mesmo o inteiro teor de uma teoria para assegurar que a conhecemos. É preciso ainda ter claras as relações entre essas proposições e o problema que elas têm o objetivo de enfrentar. Nem sempre isso aparece expresso nos textos teóricos; frequentemente é necessário relacionar diferentes proposições, às vezes, consultar outros textos do autor e inferir questões apenas implicitadas.

Louis Quéré (2018, p. 24) propõe em seu modelo praxiológico da comunicação que esta "deve ser entendida como atividade conjunta de construção de uma perspectiva comum, de um ponto de vista partilhado, como base de inferência e de ação".

Ora, é isso exatamente o que uma teoria faz: sobre um problema de conhecimento, elabora uma perspectiva (que compartilha alguns elementos de um corpo de conhecimento já estabelecido) para seu esclarecimento. A conjectura, aí, não pode ser uma simples declaração sobre a verdade objetiva das coisas, em explicitação de uma realidade social 
desde sempre presente. É um processo constituído e organizado que se oferece a debate. Na própria circulação de teorias, nas discussões acadêmicas e nos espaços de exercício dessa perspectiva, a proposição vai sendo testada para sua falibilidade e para a experiência positiva de relacionamento com outras situações e questões, práticas e/ou teóricas. É assim que a teoria se firma, se desenvolve, e pode ser considerada estabelecida. O processo da circulação é comunicacional, não como mera transmissão de informações, mas como "atividade organizante" (QUÉRÉ, 2018, 23). No que se refere a nosso objeto neste artigo, observamos que isso deve ocorrer nos circuitos em que a teoria se desenvolve.

É fácil perceber que os processos reflexivos, descritivos, inferenciais, interpretativos pelos quais o problema se constrói e as perspectivas para abordá-lo se organizam se constituem pelas estruturas e ações do texto². É por isso que devemos, para uma compreensão minuciosa de textos teóricos, não só apreender o que estes dizem, mas também perceber o que fazem através do que dizem e o que constroem em sua formulação. Não se trata de categorizar tipos de ação - se são argumentos, abduções, se raciocínios dedutivos ou indutivos, se demonstrações. O que se quer é sobretudo perceber o que é construído por tais procedimentos - como ponto de vista, como estratégia, como lógica de trabalho sobre o desafio que é o problema tratado. A questão não é categorial, mas estratégica.

Se nos apercebemos, com rigor, de tais ações, de suas lógicas próprias, estaremos preparados então para acionar essa percepção teórica a serviço de nossa pesquisa - por acionamentos que sejam pertinentes para nossos objetivos de descoberta.

\section{O que podemos fazer as teorias fazerem}

A teoria deve ser tomada como material de trabalho, na pesquisa - não é um aporte externo, pronto, que se deva abater sobre a pesquisa determinando sua direção e resultados. Inversamente, deve ser exercida a serviço da investigação, seja como apoio, por sua pertinência com relação ao que estamos investigando; seja como material flexível a ser ajustado e transferido, reflexivamente, para esse trabalho; seja ainda como material de objeções motivadas por nosso próprio objeto.

O que apresentamos a seguir neste item são algumas ações que podem ser ativadas em diferentes pesquisas. Cada uma delas implica toda uma variedade de modos, de objetivos e de relações com os problemas das pesquisas. Não são ações necessariamente estanques, a pedir acionamentos especificados - há continuidades possíveis entre uma ação e outra, combinações complexas entre ações diversas.

A lista de ações que apresentamos não é classificatória, como se fosse desejável categorizar acionamentos exercidos em uma pesquisa ou o pesquisador devesse informar sobre os usos feitos. Nem há interesse, como movimento metodológico, em fazer esse ou aquele tipo de acionamento. Quaisquer acionamentos feitos de teorias devem decorrer

2 Dessa expressão atuante podem fazer parte imagens, que mostram, e fórmulas matemáticas, que demonstram. 
de necessidades do objeto - ou seja, das próprias estratégias voltadas para o enfrentamento do problema, para apreensão e interpretação dos observáveis. Relacionam-se, também, ao que as teorias oferecem, em suas possibilidades de articulação com as questões investigadas. A lista não se pretende exaustiva - outras ações podem ser exercidas.

Não é relevante, no relato de uma pesquisa, multiplicar entradas teorizantes. Estes acionamentos serão muitos ou poucos, conforme a complexidade da pesquisa e seus objetivos. O que o item argumenta é o interesse de acionar com precisão as teorias acolhidas conforme as necessidades da investigação e seus objetivos de descoberta.

Não há regras fechadas para o acionamento teórico - este deve ser tentativamente exercido. Mas a prática na apreensão dos fazeres da própria teoria, abordados no item anterior, favorece seu uso pertinente.

\subsection{Buscar fundamentos}

As teorias são frequentemente acionadas por sua oferta de sistemas abrangentes de pensamento e conhecimento, nos quais o pesquisador inscreve sua pesquisa. As teorias são assim tomadas como paradigma. Oferecem uma perspectiva abrangente para todo um setor de conhecimentos, em que o pesquisador percebe seu objeto como pertinentemente inscrito ou a inscrever. O pesquisador busca, aí, modos de percepção de mundo disponíveis no conhecimento científico, como fundamento para, sobre essa base, elaborar suas descobertas específicas. Não cabe acionar muitas teorias com essa perspectiva de fundamentação - sob risco de dispersão, inconsistência ou contradição. É importante estar atento à forte diferença entre fundamentar a pesquisa e meramente acionar uma teoria para explicar aprioristicamente o objeto (o que não serve à produção de conhecimento).

\subsection{Usar teoria como informação consolidada sobre aspectos do mundo (contexto)}

Trata-se de teorias consideradas relevantes por informar sobre o mundo em que o objeto se encontra, se exerce, tensiona e é tensionado. A referência ao que as teorias dizem desse mundo permite conexões com o conhecimento estabelecido e com suas proposições sobre a realidade. O objeto da pesquisa empírica encontra-se enredado em um contexto, sendo direcionado por este e participando de sua constituição. A pesquisa pode, em decorrência, assumir essa realidade como conhecida - no espaço apreendido pelas citações feitas e por sua interpretação. As teorias chamadas para essa atribuição devem ser levadas a uma composição com aspectos do objeto, interagindo com especificidades deste. Não confundir, assim, com mera agregação de ângulos teóricos diversos sobre a sociedade ou - menos ainda - como demonstração de erudição genérica do pesquisador. 


\subsection{Reunir explicações prontas sobre o próprio objeto específico pesquisado}

O acionamento da referência teórica dispensa o pesquisador de pesquisar tudo a respeito de seu objeto. Pode assim se concentrar nos aspectos deste diretamente relacionados ao problema em investigação. Feita essa démarche, é preciso estar atento para o relacionamento (no processo e nas conclusões) entre os aspectos captados nas teorias prontas e os aspectos elaborados pela pesquisa - percebendo como se articulam e se, eventualmente, se tensionam. Aqui não se incluem, em geral, teorias de grande abstração, mas sobretudo teorias mais próximas do mundo empírico, relacionadas ao tipo de objeto investigado. Um dos processos de busca é a chamada pesquisa da pesquisa, em que resultados muito específicos (teorias do objeto) podem ser referidos, tanto para evidenciar o estado da arte como por expressar diversidade de ângulos investigativos (entre os quais o pesquisador vai escolher ou, melhormente, inscrever seu ângulo mais específico). As ofertas encontradas elucidam aspectos que podem então dispensar abordagem lembrando-se, entretanto, que o que se assume como conhecimento pronto cria um ponto cego para descobertas: pois o que já é conhecido não é investigado.

\subsection{Fazer a teoria atestar afirmações que fazemos}

São acionadas proposições teóricas estabelecidas que o pesquisador considera confirmadoras de proposições da própria pesquisa, e que, não sendo investigadas ou argumentadas em maior profundidade por esta, poderiam suscitar dúvidas e objeções. As referências de atestação, além disso, conectam (diretamente ou por proximidade) perspectivas da pesquisa em curso com o conhecimento estabelecido. Essa ação deveria ser adotada com comedimento - eventualmente encontramos artigos em que, para cada proposição, o autor vai buscar uma referência de atestação, como se todo conhecimento em produção tivesse que se amparar em proposições já dadas, o que transforma a reflexão em colagem. É interessante reservar esse acionamento para os tópicos em que efetivamente se percebe uma necessidade de confirmação ou uma probabilidade de objeções. Um cuidado adicional: se todas as proposições de uma pesquisa forem relacionadas a atestações, isso pode significar que a pesquisa não faz mais que reafirmar conhecimentos estabelecidos.

\subsection{Obter indicações metodológicas}

Nas teorias, encontram-se pistas para o pesquisador elaborar sua própria metodologia - modos de fazer - seja por indicação expressa dos textos teóricos referidos, seja porque o pesquisador constata que tais e tais caminhos foram explorados na construção teórica de referência e percebe a possibilidade de transferir os procedimentos para o que investiga. Observe-se que os textos teórico-metodológicos apresentam proposições abstratas - referindo ou não exemplos de aplicação. A transposição direta não é adequada: 
as singularidades da situação estudada e do problema investigado pedirão sempre ajustes metodológicos para o trabalho da especificidade. É por isso que uma aprendizagem de metodologias diversas é importante. Não para que o pesquisador tenha um cardápio de alternativas em que faça escolhas prontas; mas sim para incorporação de práticas diferenciadas que lhe deem flexibilidade e sabedoria para elaborar, sob medida, as táticas e protocolos mais pertinentes a seu objeto.

\subsection{Elaborar questões de horizonte}

$\mathrm{Na}$ medida em que uma teoria, ao resolver problemas determinados (fazendo proposições e conjecturas), oferece perspectivas abrangentes em nível abstrato, permite a apreensão de toda uma ordem de questões. Não raro, sistemas teóricos com alguma abrangência sugerem explícita ou implicitamente questões de horizonte. Inscrever um objeto em tal perspectiva implica também trabalhar com as questões de horizonte aí pertinentes. Eventualmente, o próprio pesquisador desenvolverá suas questões de horizonte a partir de articulações entre diferentes teorias. Nesse caso, a questão de horizonte pode surgir de espaços lacunares ou de contraposição entre teorias diversas a respeito de uma mesma ordem de problemas. Quando o pesquisador explicita uma questão de horizonte, este é um passo preliminar. O problema, ao ser especificado - passo fundamental - deve desenvolver efetiva articulação; ou levar a revisões da própria questão de horizonte.

\subsection{Buscar estimulação heurística}

A palavra heurística refere a arte (a habilidade prática) de fazer descobertas e encontrar soluções. Tomar uma teoria por suas possibilidades heurísticas significa acionar proposições desta não pelo que explicam sobre a realidade do mundo e sim pelo que oferecem como pista para a busca de conhecimento sobre os processos que observa. Nesse caso, não buscamos os conceitos ou categorias oferecidas pela teoria. Não queremos encontrar no objeto o que a teoria afirma, nem assumir as categorias expressas e as relações afirmadas - e sim fazer perguntas e observações, aí inspiradas, para descobrir o que o próprio objeto desvela nessa angulação. Se as coisas se passam do modo teoricamente afirmado, o que podemos descobrir sobre a singularidade de nosso objeto? Esse acionamento de ângulos de busca e não de respostas, é particularmente interessante, pois evita que a teoria aja aprioristicamente sobre nosso objeto de pesquisa, pretendendo tê-lo explicado antes mesmo que seja investigado.

\subsection{Tensionar conhecimentos do senso comum}

As teorias não apenas explicam situações do mundo. Paralelamente, podem tensionar os modos pelos quais a situação em pauta se interpreta cotidianamente. A teoria não deve 
substituir o senso comum - deve ser acionada como procedimento de compreensão e aprofundamento deste.

Não estamos fazendo aqui, portanto, a habitual referência a uma pretendida ruptura do conhecimento científico com o senso comum. Estudos êmicos não rompem com o senso comum: procuram, diversamente, apreender as lógicas deste para compreender o que aí ocorre. A comunicação solicita uma perspectiva êmica, pois importa sintonizar o que a sociedade experimenta, produz e testa em suas práticas interacionais. Essa ação de tensionar o senso comum corresponde à busca de sua qualificação através de uma percepção mais aguda do sentido daquelas lógicas; dos âmbitos específicos de validade destas; dos espaços em que a validade vacila; e das eventuais consequências de expansões menos adequadas.

\subsection{Fazer teorias tensionarem teorias}

Diferente de decidir: uma é certa, a outra é errada. Em vez disso, trata-se de perquirir âmbitos de validade diferentes; observar que aspectos do objeto de pesquisa sugerem a adequação de uma teoria, que aspectos sugerem outra. E ainda: perceber como as diferentes proposições teóricas se compõem, se contrapõem e se tensionam - em termos abstratos ou ao serem exercidas em relação ao objeto investigado. Esse tensionamento corresponde, também, a perceber as diferentes problematizações que as teorias postas em comparação assumem como seu desafio próprio. Não se limita, assim, a cotejar proposições diferenciadas, devendo abarcar também os modos como as teorias constroem seus problemas e apresentam estratégias para enfrentá-las. Acionamentos deste tipo ajudam a evitar relações menos pertinentes entre teoria e objeto.

\subsection{Tensionar a teoria por nosso objeto de pesquisa}

Se uma teoria resolve totalmente nosso objeto, a pesquisa seria desnecessária. Em que aspectos não resolve? Precisa ser complementada, reajustada? Não se trata de o pesquisador estar ou não de acordo com a teoria. Se esta não é interessante ou pertinente para o objeto, não há o que tensionar - simplesmente não deve ser acionada. O tensionamento supõe uma de duas situações. Ou a teoria é interessante para o objeto - entretanto não se mostrando suficiente para este, devendo portanto ser estirada ou redirecionada. Ou a teoria se contrapõe à abordagem decidida pelo pesquisador, e sua crítica deve ser elaborada para expressar os limites da teoria e os modos pelos quais a proposta do pesquisador permite perceber esses limites e superá-los. Ainda aqui, não se trata de simples desacordo, mas de um uso efetivo da teoria tensionada para avançar além dela. Do tensionamento exercido sobre a insuficiência ou sobre o desajuste entre teoria e objeto podem surgir derivações, que caracterizam esse avanço. 


\subsection{Fazer transferências da teoria para situações semelhantes, mas diversas}

Muito frequentemente esquecemos que as teorias das diversas ciências humanas e sociais foram desenvolvidas não apenas abstratamente, mas também com base em perquirições sobre situações do mundo e pela construção de objetos de investigação. Por mais que a situação de interesse para nossa pesquisa empírica possa ser assemelhada àqueles objetos, muito raramente seria a mesma. Se assumimos uma semelhança de nosso problema de pesquisa com aqueles que permitiram a geração da teoria adotada, isso deve caracterizar uma boa escolha. Entretanto, não basta perceber as semelhanças, sendo importante ainda detectar as especificidades de nosso objeto em investigação que o fazem afinal diverso, malgrado as semelhanças. Essa especificidade solicita, então, ao lado de tensionamentos pertinentes (ver tópico 10, acima), um trabalho de transferência, com ajustes para adequação a nosso objeto. Não se deve confundir, portanto, transferência com mera aplicação de proposições da teoria a nosso objeto.

\subsection{Desentranhar conhecimentos comunicacionais em teorias de outras CHS}

Um trabalho teórico relevante na área da comunicação é o de acionar teorias sobre comunicação produzidas em outras CHS - buscando tensioná-las por um ângulo pertinente a nossa pesquisa. Somos pesquisadores em comunicação: nossos objetivos incluem a possibilidade de desentranhar perspectivas propriamente comunicacionais, observando teorias de outras CHS como um espaço de garimpo produtivo, redirecionando reflexões e descobertas a serviço de objetos comunicacionais. Como as primeiras perguntas e hipóteses sobre o fenômeno comunicacional vêm sendo produzidas e ofertadas pelas demais CHS, uma preocupação do pesquisador em comunicação deve ser justamente a de acionar criticamente as teorias que trazem essas ofertas para dar passos adicionais, desenvolvendo outras hipóteses e perguntas - que não serão feitas pelas disciplinas de origem, justamente porque extrapolariam seu horizonte de interesse.

\section{Conclusões}

A citação de Bourdieu, que adotamos como epígrafe para este artigo, faz basicamente duas coisas: (a) oferece um critério de qualidade para a teoria3; e (b) estabelece, assim, uma meta para os pesquisadores, que é a de assegurar essa qualidade na pesquisa: fazer a teoria se realizar e se dissipar em seu trabalho.

Aceitando o critério e a meta, acionamos esta como base para o problema central do artigo, que envolve a questão como?. Decorrem dessa questão algumas perguntas subsidiárias que direcionam a elaboração do artigo.

3 É claro que "verdadeira teoria" não corresponde a teoria verdadeira - que diz a verdade; mas sim a teoria que é teoria mesmo, e por isso boa teoria. 
A proposição de Bourdieu mostra um elemento de ordem prática, no trabalho a ser realizado, em articulação estreita com a própria ideia de teoria; e mais que isso: a própria teoria é o sujeito de verbos que implicam atividade, "se realizar e se dissipar".

Antoine Compagnon, observando o mesmo processo, mas agora na perspectiva do pesquisador que aciona a teoria, expressa de modo vigoroso a energia produtiva desse trabalho: "[a citação] não tem sentido fora da força que a move, que se apodera dela, a explora e a incorpora" (COMPAGNON, 2007, p. 47).

Valorizando os aspectos práticos no processo da pesquisa (BRAGA, 2011), e sabendo da frequência com que estes dois elementos centrais de nossa atividade se apresentam em disjunção, percebemos, tanto na meta de Bourdieu como em nossa proposta, a importância da superação do dualismo.

O que o artigo faz, a partir daí, é rastrear ações e decisões que relacionam prática e teoria. Vai encontrar articulações em três momentos principais, cada um deles comportando uma variedade de ações possíveis: na geração da teoria; na formulação desta, como parte requerida em seu processo de circulação; e nos exercícios e acionamentos subsequentes da teoria.

Esses três momentos são organizados, no texto, em itens separados, para efeito de clareza expositiva, mas são necessariamente imbricados, pois os fazeres de cada um só produzem sentido pelos subsídios que buscam nos dois outros, e pelo que propõem a cada um deles em retorno. Os acionamentos da teoria fazem parte do processo de sua circulação, do debate de suas estratégias - tanto para composições com o problema aí trabalhado como para a produção de novas teorias. A formulação integra o trabalho de enfrentamento do problema de partida.

Assim, a teoria que circula não é uma peça cristalizada, que se possa aplicar sobre investigações em curso, como um molde para os objetos destas. O trabalho articulador se exerce nas duas direções: da teoria sobre o objeto, pelos fazeres que traz em suas estratégias de origem; do objeto sobre a teoria, pela variedade de serviços que exige desta, em arranjos proativos.

A verdadeira teoria não se exerce por si, por seus dizeres abstratos, mas sim, inicialmente, pelas ações que faz sobre seu próprio problema de origem e em suas estratégias na construção de soluções. No acionamento, disponibiliza tais ações à interação transformadora com os problemas e estratégias da pesquisa para a qual é chamada. Torna-se verdadeira teoria pelas ações do pesquisador que saiba exercê-la e tensioná-la.

José Luiz W. J. G. Braga é professor titular no PPG em Ciências da Comunicação da Unisinos desde 1999, que coordenou de 2002 a 2004. É pesquisador PQ 1A do CNPq, doutor pela Université de Paris II, Institut Français de Presse (1984) e mestre em Educação pela Florida State University 
(1972). Foi professor na Universidade Federal da Paraíba (UFPB) e na Universidade de Brasília (UnB). Foi presidente da Compós, 1993-95.

jbraga@unisinos.br

\section{Referências}

BRAGA, J. L.W. A prática da pesquisa em comunicação: abordagem metodológica como tomada de decisões. E-Compós, Brasília, vol. 14, nº 1, jan./abr. 2011, p. 1-32.

BOURDIEU, P.; WACQUANT, L. J. D. Réponses: pour une anthropologie réflexive. Paris: Seuil, 1992. COMPAGNON, A. O trabalho da citação. Belo Horizonte: Editora UFMG, 2007.

GUSMÃO, L. O fetichismo do conceito. Limites do conhecimento teórico na investigação social. Rio de Janeiro: Topbooks, 2012.

POPPER, K. A lógica e a evolução da teoria científica. In: POPPER, K. A vida é aprendizagem: epistemologia evolutiva e sociedade aberta. Lisboa: Edições 70, 2001. p. 17-34.

QUÉRÉ, L. De um modelo epistemológico da comunicação a um modelo praxiológico. In: VEIGA FRANÇA, V.; SIMÕES, P. (Orgs.). O modelo praxiológico e os desafios da pesquisa em comunicação. Porto Alegre: Sulina, 2018. p. 15-48.

Artigo recebido em 01/10/2018 e aprovado em 13/11/2018. 